
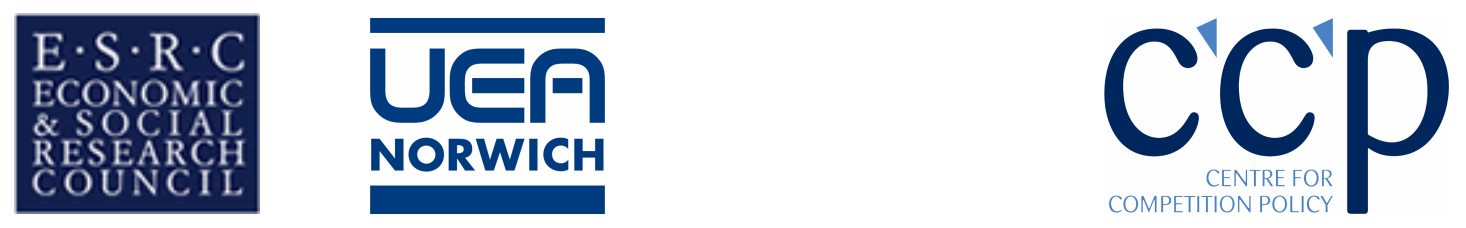

\title{
Do Consumers Switch to the Best Supplier?
}

by

\author{
Chris M. Wilson \\ Department of Economics, University of Oxford \\ \& \\ Catherine Waddams Price \\ ESRC Centre for Competition Policy and Norwich Business \\ School, University of East Anglia
}

\section{CCP Working Paper 07-6}

\begin{abstract}
This paper suggests that the ability of consumers to choose accurately between alternative suppliers is substantially limited even in a relatively simple and transparent market. Across two independent datasets from the UK electricity market we find, on aggregate, that those consumers switching exclusively for price reasons appropriated between a quarter and a half of the maximum gains available. While such outcomes can be explained by high search costs, the observation that at least a fifth of the consumers actually reduced their surplus as a result of switching cannot. We consider and reject several alternative explanations to pure decision error.
\end{abstract}

July 2007 (Original Version: May 2006; second version: April 2007)

JEL Classification Codes: LOO, D83

Keywords: Search Costs, Switching Costs, Decision Errors, Misselling. 


\section{Acknowledgements:}

We are very grateful to Michael Waterson for extensive and valuable discussions, and to participants at the CCRP workshop in Birmingham 2007, the workshop for Consumer Behaviour and Bounded Rationality at UCL 2006 and EARIE 2005. Thanks also go to Tina Chang, Steve Davies, Luke Garrod, James Harvey, Morten Hviid, Khac Pham, Laurence Mathieu, Peter Moffatt, Alistair Munro, Jeremy Tobacman, Matthew Olczak, John Vickers and Matthijs Wildenbeest for their help and comments. A previous version of the paper was titled 'Irrationality in Consumers' Switching Decisions: When More Firms May Mean Less Benefit". The support of the Economic and Social Research Council (UK) is gratefully acknowledged. The usual disclaimer applies.

Contact details:

Christopher Wilson, Department of Economics, University of Oxford, Manor Road Building, Manor Road, Oxford OX1 3UQ, UK.

christopher.wilson@economics.ox.ac.uk 


\section{Introduction}

Competition policy and other policy initiatives in markets as diverse as health and education are increasingly based on the presumption that consumers can play a positive role in generating market competition by choosing to trade with the supplier that best suits their needs. However, consumers may be unable to perform this role and competitive forces may be consequently weakened for several reasons. Consumers may be unwilling to change suppliers because of switching costs, unaware of alternative suppliers because of search costs or may face difficulties in evaluating and comparing different suppliers' offers because of cognitive decision-making costs ${ }^{1}$. While previous empirical research has largely focussed on identifying the effects of switching costs, this paper investigates the importance of the last two possibilities by analysing empirically the accuracy with which switching consumers choose their best available alternative supplier.

We exploit two independent datasets from the UK electricity market where consumers have been free to switch away from their regional incumbent to one of several entrants since the market's liberalisation in 1999. In such a market, we would expect consumers' switching decisions to be relatively accurate for several reasons. First, almost all households consume electricity and for many, it forms a significant part of their household budget. Second, the market is relatively simple as firms supply a near-homogenous good and at the time of our surveys each supplier effectively offered only a single tariff option. Third, the market is transparent with the industry regulator and several online price comparison services providing many forms of advice and tariff information. Yet, despite such market conditions, this paper suggests that the inaccuracy of consumers' switching decisions remains substantial. Even when focussing only on the consumers who, when asked, indicated that they had switched suppliers exclusively for price reasons, we find that across the two datasets and under a range of assumptions, only $8-19 \%$ of consumers switched to the firm offering the highest surplus and, in aggregate, switching

\footnotetext{
${ }^{1}$ See Farrell and Klemperer (2006) for a review of the market power effects of switching costs, Baye et al (forthcoming) for search costs, and Gabaix et al (2005) for cognitive costs.
} 
consumers appropriated only between $28 \%$ and $51 \%$ of the maximum gains available to them. While such behaviour is wholly consistent with the behaviour of rational consumers facing high search costs, the additional finding that $20-32 \%$ of switching consumers appear to have lost surplus through their choice of supplier is not. These consumers lost an average £1435 per year in increased bills, apart from any other switching costs they may have incurred.

Very little previous research has examined empirically the switching accuracy of consumers. As part of a much wider investigation into the effects of entry in the New York State telephone market, Economides et al (2006) suggest that $42 \%$ of consumers switched to a more expensive supplier, resulting in an average loss of $\$ 4.33$ per month. Giulietti et al (2005) suggest there may be consumer inaccuracy in the UK gas market by showing that consumers' (binary) switching decisions appear unrelated to the monetary gains available from doing so, especially for consumers who expect price differences to be transitory. A larger literature however, has analysed the widespread potential for consumers to select a non-cost minimising option from a menu of tariffs offered by the same firm. Agarwal et al (2006), for example, suggest that over $40 \%$ of consumers selected the more expensive tariff when offered the option of two credit card contracts in a market experiment by a US bank, while Lambrecht and Skiera (2006) use data from a German internet provider to estimate that around a third of consumers chose a more expensive fixed rate tariff, and over half of these paid more than double the cheapest alternative. The proposed explanations for such choices fall into three broad categories. First, consumers may show a preference for certain tariff structures, such as flat-rate fees (Lambrecht and Skiera 2006). We find no support for such an explanation as the gains from switching are largely unrelated to any associated change in tariff structure. Second, in comparing tariffs, consumers may weight inappropriately the various components of a tariff or price, such as the introductory rate, shipping charge or state-tax rate (e.g. Ausubel 1999, Hossain and Morgan 2006, Ellison and Ellison 2006, respectively). This explanation is not supported by our data which show that the gains made by consumers who switched to suppliers offering a potentially focal 'dual-supply' 
discount are not significantly different from the gains made by other consumers. Third, consumers may evaluate alternative suppliers' tariffs using an incorrect prediction of their own future consumption (Miravete 2003, Della Vigna and Malmendier 2004, 2006). This explanation also appears unconvincing as all results are derived from consumers' own (expenditure) beliefs and remain robust across consumption variations of plus and minus ten percent.

Highlighted by the recent widespread allegations about such practices within the industry, one plausible explanation of the results concerns the pressurising or misleading influence of suppliers' sales activities. However we find that the accuracy of consumers' choices are not significantly related to the self-reported influence of a sales agent; nor does an increased number of regional competitors, which might result in increased sales activity, consistently reduce the accuracy of decisions. Instead, the paper concludes that consumers' switching inaccuracy is consistent with pure decision error. This finding underlines the importance of the growing research into the incentives firms may face to exploit or induce consumer confusion - see Ellison and Ellison (2005) or Armstrong and Spiegler (2007) for a further discussion.

Section 2 provides a brief theoretical foundation for the measures of the gains from switching that are later calculated. Section 3 introduces the market, the data and the calculation procedures. The descriptive results are presented in section 4. Section 5 proposes some potential explanations for the results and presents some further analysis to test them; section 6 concludes.

\section{Theory}

To analyse the accuracy of consumers' switching decisions it is necessary to calculate both the actual gains in surplus that each consumer made through their choice of new supplier and the maximum possible gains that each consumer could have achieved by switching to their best supplier (given their demand characteristics). We now present some simple measures to form the basis of such calculations. 
Consider consumer $i$ 's decision to switch away from his old supplier, $o$, to a new supplier, $n$, chosen from his set of alternative suppliers, $S_{i}$. Assuming that consumer $i$ cares only about the tariff offered by each supplier, equation (1) describes the approximate annual gain in consumer surplus (excluding switching costs) from deciding to switch from supplier $o$ to supplier, $n$,

$$
\Delta C S_{i}=C S_{i}^{n}-C S_{i}^{o} \square\left[u_{i}\left(C_{i}^{n}\right)-E\left(C_{i}^{n} ; T^{n}\right)\right]-\left[u_{i}\left(C_{i}^{o}\right)-E\left(C_{i}^{o} ; T^{o}\right)\right]
$$

where the consumer surplus received at any firm $j$ consists of the utility from consuming $C_{i}^{j}$ homogenous units of electricity annually, $u_{i}\left(C_{i}^{j}\right)$, minus the associated bill expenditure, $E\left(C_{i}^{j} ; T^{j}\right)$, which depends on firm $j$ 's tariff, $T^{j}$. With the use of a revealed preference argument to ensure that $u_{i}\left(C_{i}^{o}\right)-E\left(C_{i}^{o} ; T^{o}\right) \geq u_{i}\left(C_{i}^{n}\right)-E\left(C_{i}^{n} ; T^{o}\right)$ an upper bound for the actual gains made from such a switching decision, $x_{i}^{s w}$, is constructed by comparing the expenditures that would result from consuming the level of post-switching consumption, $C_{i}^{n}$, at each supplier, (2). Such an upper bound is very close to the approximate change in surplus described by (1) when demand is highly price inelastic, as in the electricity market (Baker et al 1989).

$$
\Delta C S_{i} \leq x_{i}^{s w} \equiv E\left(C_{i}^{n} ; T^{o}\right)-E\left(C_{i}^{n} ; T^{n}\right)
$$

Similarly an upper bound for the maximum possible gains that consumer $i$ could have made by switching away from supplier $o, x_{i, o}^{\max }$, can be constructed by comparing the expenditure at $i$ 's old supplier with the lowest possible expenditure available from the set of alternative suppliers, $S_{i}$, (3). One final upper bound measures the gains consumer $i$ would have expected to make by randomly selecting an alternatively supplier, $x_{i, o}^{\text {mean }}$. (4) compares the expenditure at $i$ 's old supplier with the average expenditure across supplier $i$ 's set of alternative suppliers.

$$
x_{i, o}^{\max }=E\left(C_{i}^{n} ; T^{o}\right)-\min _{k \in S_{i}} E\left(C_{i}^{n} ; T^{k}\right) \quad \geq 0
$$




$$
x_{i, o}^{\text {mean }}=E\left(C_{i}^{n} ; T^{o}\right)-\operatorname{mean}_{k \in S_{i}} E\left(C_{i}^{n} ; T^{k}\right)
$$

Fully rational and informed consumers who care only about the tariffs offered by each firm would select the alternative supplier that offers the maximum reduction in expenditure, $x_{i}^{s w}=x_{i, o}^{\max }$. If consumers are rational but not fully informed, perhaps due to the existence of search costs, they may be willing to select a supplier that does not offer the maximum reduction in tariff expenditure, $x_{i}^{s w}<x_{i, o}^{\max }$. However, as consumers always retain the option of not switching, they should never make negative gains and so we expect $x_{i}^{s w} \in\left[0, x_{i, o}^{\max }\right]$.

\section{Calculations}

This section uses the measures constructed in section 2 to analyse the switching accuracy of two sets of consumers in the UK electricity market. After an introduction to the market in section 3.1, section 3.2 presents the data and illustrates how the UK electricity market is particularly well suited for such an analysis. Section 3.3 explains how the final calculations are made.

\subsection{The Market}

Since liberalisation of the UK residential electricity market was completed in mid 1999, electricity suppliers have been permitted to enter each of the fourteen regional markets to compete with the original regional incumbent. While few new suppliers chose to enter the industry, many regional incumbents took the opportunity to enter most, if not all, of the regions in which they had not previously been incumbent, as did the national gas supplier, British Gas. Consumers were free to switch away from their regional incumbent (or any subsequent supplier) with twenty-eight days notice and no financial penalty. In the subsequent eight years about half of all energy consumers moved away from their regional incumbent. 
An example of the range of tariffs on offer to consumers is displayed in Table 1. As tariffs vary by region and by time, Table 1 presents a typical snapshot of the tariffs offered within an example region, the Midlands, in June 2000. Suppliers are obliged to offer tariffs for three possible consumer payment methods - standard credit, direct debit and prepayment, but in practice, only offered a single tariff per payment method ${ }^{2}$.

Suppliers typically offer two-part tariffs, with some offering three-part tariffs that contain an additional marginal rate for higher levels of consumption beyond some threshold. The majority of electricity suppliers who are also active in the gas market increasingly participate in mixed bundling by offering a dual-supply discount to those consumers who choose to buy both forms of energy. While it is common for suppliers to approach consumers directly in the hope of persuading them to switch, it is rare for suppliers to use upfront discounts or incentives.

Since liberalisation, many internet-based price comparison sites have offered consumers advice in choosing between suppliers. Despite the industry regulator and consumer body endorsing the use of several comparison sites, their popularity remained limited in the period of our studies, with only $10 \%$ of surveyed consumers having used them in 2003 (OFGEM 2004).

\footnotetext{
${ }^{2}$ More recently suppliers have offered a wider choice of tariffs, including 'capped' tariffs, but these were not available at the time of the consumer decisions analysed here.
} 
Table 1: Example Set of Tariffs (Midlands Region, June 2000, in pence)

\section{Payment Method:}
Credit
Direct Debit
Prepayment

Electricity Supplier:

\begin{tabular}{ccccccc} 
Fixed & Rate1 & Rate2 & & Fixed & Rate1 & Rate2 \\
\hline \hline 2159 & 6.72 & - & & 2094 & 6.52 & - \\
0 & 10.57 & 5.65 & & 0 & 9.01 & 5.65 \\
2848 & 6.38 & 6.28 & & 1856 & 6.38 & 6.28 \\
3541 & 5.99 & - & & 2491 & 5.99 & - \\
4982 & 5.46 & - & & 4026 & 5.46 & - \\
3048 & 5.86 & - & & 3048 & 5.86 & - \\
0 & 9.14 & 5.68 & 0 & 8.19 & 5.68 \\
4922 & 5.30 & - & & 4637 & 5.21 & - \\
0 & 11.97 & 5.34 & & 0 & 10.82 & 5.34 \\
1873 & 6.08 & - & & 1873 & 6.08 & - \\
5408 & 5.26 & - & 4883 & 5.01 & - \\
3116 & 6.29 & - & & 3053 & 6.16 & - \\
1966 & 5.67 & - & & 1886 & 5.44 & - \\
3045 & 5.86 & - & & 2954 & 5.68 & - \\
3595 & 7.25 & - & & 2595 & 7.25 & - \\
4721 & 5.76 & - & & 4091 & 5.76 & - \\
\hline
\end{tabular}

\begin{tabular}{ccc} 
Fixed & Rate1 & Rate2 \\
\hline \hline 3734 & 6.72 & - \\
0 & 10.28 & 6.17 \\
3713 & 6.72 & - \\
5116 & 5.99 & - \\
4497 & 7.77 & - \\
9202 & 7.80 & - \\
3990 & 6.52 & - \\
3734 & 6.72 & - \\
4112 & 6.72 & - \\
3990 & 6.52 & - \\
3734 & 6.72 & - \\
3990 & 6.52 & - \\
3734 & 6.71 & - \\
4523 & 7.39 & - \\
7388 & 7.68 & - \\
8669 & 5.76 & - \\
\hline
\end{tabular}

\begin{tabular}{ccc} 
Threshold & & $\begin{array}{c}\text { Dual-Supply } \\
\text { Discount }\end{array}$ \\
\cline { 1 - 1 } 900 & & - \\
2392 & & - \\
- & & 250 \\
- & & - \\
- & & - \\
1092 & & - \\
- & & - \\
728 & & - \\
- & & - \\
- & & 1050 \\
- & & - \\
- & & - \\
- & & - \\
- & & - \\
- & & - \\
& &
\end{tabular}

Each supplier offers a tariff across three payment methods. Each tariff consists of an (possibly zero) annual fixed fee, Fixed, with an additional marginal rate, Rate1 in pence/kWh, and, in some cases, a second marginal rate, Rate2, for consumption over and above some annual breakpoint, Threshold (in kWh). Dual supply discounts are offered only to credit or direct debit consumers (except by East Midland/Powergen who offer them to all consumers). Additional discounts are labelled with numbers in brackets - (1) 3\% off Direct Debit if bill exceeds £10.50 (2) £8.40 off credit and direct debit. 


\subsection{Data}

Two datasets were constructed from two independent, cross-sectional, faceto-face surveys of consumers in England, Scotland and Wales. The EA survey (Cooke et al 2001) was conducted between March and August 2000 and was intentionally biased towards low-income consumers ${ }^{3}$. Of the 3417 consumers surveyed, 523 had switched electricity suppliers and, of these, 373 had a full set of responses to questions relevant for the analysis. In contrast, the CCP survey, was designed to be representative of the general population and was conducted for the ESRC Centre for Competition Policy in June $2005^{4}$. Of the 2027 consumers surveyed, 370 had switched suppliers in the previous three years, and 245 furnished useable responses. While the presence of a lowincome bias and missing information limit our ability to draw general inferences about how switching behaviour varies with consumer characteristics, we view the measurement of switching accuracy within each of these samples as informative.

A major constraint on the ability to measure consumers' switching accuracy arises from the possibility that consumers switched for reasons other than price. Whilst non-price gains are likely to be small in a near-homogeneous market like electricity, they may arise from two sources. First, although the reliability of supply is independent of the supplier (since it depends upon the vertically separated distribution function), consumers may perceive that firms vary in attributes such as customer service or environmental awareness. Second, in addition to the possible monetary benefits of being supplied electricity and gas by the same supplier, for which we account for, consumers may perceive some non-price, practical benefits from having to deal with only one supplier. To eliminate these possibilities, we restrict our analysis to a subset of consumers who stated that their switching decision was motivated purely by price. Specifically, two sub samples are created that contain 318 and 154 consumers respectively who, when asked, cited only differences in

\footnotetext{
${ }^{3}$ The EA survey and its initial analysis were funded by the Electricity Association - an early description of consumers' choices and errors is contained in Waddams Price (2003).

${ }^{4}$ The CCP survey was designed to analyse search and switching behaviour across eight different product markets as analysed by Chang and Waddams Price (forthcoming). Here, only the data from the electricity market is used.
} 
price as a reason for switching and did not mention factors such as the quality of service, the provision of 'environmental' tariffs or the practical benefits of being dual-supplied. A full summary of the consumers' (multiple) reasons for switching suppliers is presented in Tables $2 \mathrm{a}$ and $2 \mathrm{~b}^{5}$.

Tables 2a and 2b: Reasons for Switching Suppliers across the Two Datasets

\begin{tabular}{lc} 
Reason for Switching (EA) & Mean \\
\hline \hline Cheaper & 0.77 \\
Dual Supply Discounts & 0.10 \\
Influence of Sales Agent & 0.10 \\
'Conned'/Unaware of switching & 0.03 \\
Poor Service from Old Supplier & 0.03 \\
Better Service & 0.02 \\
No Standing Charge & 0.01 \\
Other & 0.05 \\
\hline $\mathrm{n}$ & 373
\end{tabular}

\begin{tabular}{lc} 
Reason for Switching (CCP) & Mean \\
\hline \hline Better Prices/Rates & 0.86 \\
Better Service/Quality & 0.19 \\
Not Satisfied with Old Supplier & 0.11 \\
Dual Supply & 0.06 \\
Environmental Tariffs & 0.03 \\
Other & 0.10 \\
\hline $\mathrm{n}$ & 245
\end{tabular}

\subsection{Calculating the Gains from Switching}

This section provides further details of how the bound measures constructed in section 2 are used with the selected data samples to calculate consumers' switching accuracy.

To focus only on the accuracy of consumers' choice of supplier and not on the choice of payment method or gas supplier, all calculations are made by comparing suppliers' relevant tariffs whilst treating each consumer's known choice of payment method(s) and gas supplier as given. Specifically, the calculations are made using equations (5)-(7), where the tariff of each supplier, $T_{t r}(m, g)$, varies according to the consumer's date of switching, $t$, electricity supply region, $r$, choice of gas supplier, $g$, and choice of payment method, $m$, (both before and after switching).

$$
x_{i}^{s w}=E\left[\hat{C}_{i}^{n} ; T_{t r}^{o}\left(m^{o}, g\right)\right]-E\left[\hat{C}_{i}^{n} ; T_{t r}^{n}\left(m^{n}, g\right)\right]
$$

\footnotetext{
${ }^{5}$ The EA respondents were asked to provide an unstructured explanation for why they had switched, which was later coded into an exclusive list of reasons, whereas the CCP respondents were asked to indicate up to three reasons from a list of possible options. No distinction was made between price and non-price benefits of dual-supply and so all consumers who cited dual-supply as a reason for changing suppliers are eliminated from the sample.
} 


$$
\begin{aligned}
& x_{i, s}^{\max }=E\left[\hat{C}_{i}^{n} ; T_{t r}^{o}\left(m^{o}, g\right)\right]-\min _{k \in S_{r}} E\left[\hat{C}_{i}^{n} ; T_{t r}^{k}\left(m^{n}, g\right)\right] \\
& x_{i, s}^{\text {mean }}=E\left[\hat{C}_{i}^{n} ; T_{t r}^{o}\left(m^{o}, g\right)\right]-\operatorname{mean}_{k \in S_{r}} E\left[\hat{C}_{i}^{n} ; T_{t r}^{k}\left(m^{n}, g\right)\right]
\end{aligned}
$$

Using a time series of the unique tariff offered by each supplier per payment method $^{6}$, an estimate of consumption, $\hat{C}_{i}^{n}$, was calculated from each consumer's own estimate of their average electricity expenditure ${ }^{7}$. Such an approach offers two advantages. First, it is probably more accurate as consumers are more likely to recall their expenditure than their consumption. Second, and more importantly, all gains are calculated in a way that is consistent with consumers' own consumption beliefs, so that any inaccurate consumer choices cannot be attributed to consumers' incorrect consumption estimates. A potential drawback, however, comes from the possibility that each consumer's expenditure beliefs may have changed in the intervening period between the time of the switching decision and the time of the survey. We take two approaches to allow for this possibility and to add further robustness to the findings. First, we identify a subgroup of the EA consumers whose survey responses indicated that their consumption was highly price inelastic, and stable over time, and demonstrate that these do not differ significantly from the rest of the sample ${ }^{8}$. The insignificant difference supports the claims that i) the constructed upper bounds form close approximations to the true gains from switching and ii) consumption is likely to be stable between the time of switching and the time of the survey. Second, we repeat the three measurements for all consumers using consumption levels which are plus and minus ten percent of our original estimate.

\footnotetext{
${ }^{6}$ The tariff dataset builds on that used by Giulietti et al (2005) and was obtained by either contacting suppliers directly or downloading bimonthly tariffs from a consumer advice website, www.which.co.uk or the energy consumer body, www.energywatch.org.uk.

${ }^{7}$ Consumers were asked to provide an estimate of their expenditure on a weekly, fortnightly, monthly or quarterly basis as they preferred.

${ }^{8}$ The subgroup of consumers indicated high price inelasticity by replying "the same" to the following questions: $\mathrm{Q}$. If the cost of electricity went down would you use more electricity or use the same electricity and use the savings for something else?, and Q. If the cost of electricity went up would you use less electricity or use the same electricity?, and further indicated a stable consumption pattern by replying "No" to the following questions, Q. Has there been any change in your household's circumstance in the last 2-3 years that affected your fuel consumption?, and Q. Has your household's electricity ever been disconnected because of unpaid electricity bills?
} 
Whilst the CCP dataset is sufficiently rich to provide all the required information, the EA dataset does not provide all the necessary variables directly from the survey because of uncertainty about the exact date of switching and of any change in payment method. To proceed we derive the EA calculations under the four most likely scenarios and compare the results for robustness. This leads to the specifications, Oct99nochange, Oct99change, Jun00nochange and Jun00change, which are detailed fully in the appendix.

\section{Descriptive Results}

Figure 1 plots the estimated actual gains from switching against the maximum gains available for all consumers (averaging across the EA specifications outlined above). Two immediate observations can be made. First, many of the consumers have not appropriated the maximum gains available, as indicated by the points located below the $45^{\circ}$ line. This is consistent with the behaviour of rational consumers facing search costs and with experimental evidence that suggests consumers often search too little (Sonnemans 1998 and Tenorio and Cason 2002). Second, however, a significant fraction of switchers appear to have actually lost surplus by switching to a more expensive supplier, as indicated by the points below the x-axis, a finding which is inconsistent with the behaviour of rational consumers motivated to switch only by price. To explore the findings in more detail, Table 3 displays the main results derived from the original estimates of consumption and Table 4 includes the results with the alternative consumption levels. 
Figure 1: The Actual Gains Made from Switching relative to the Maximum Gains Available, CCP and EA (pooled specification) Datasets

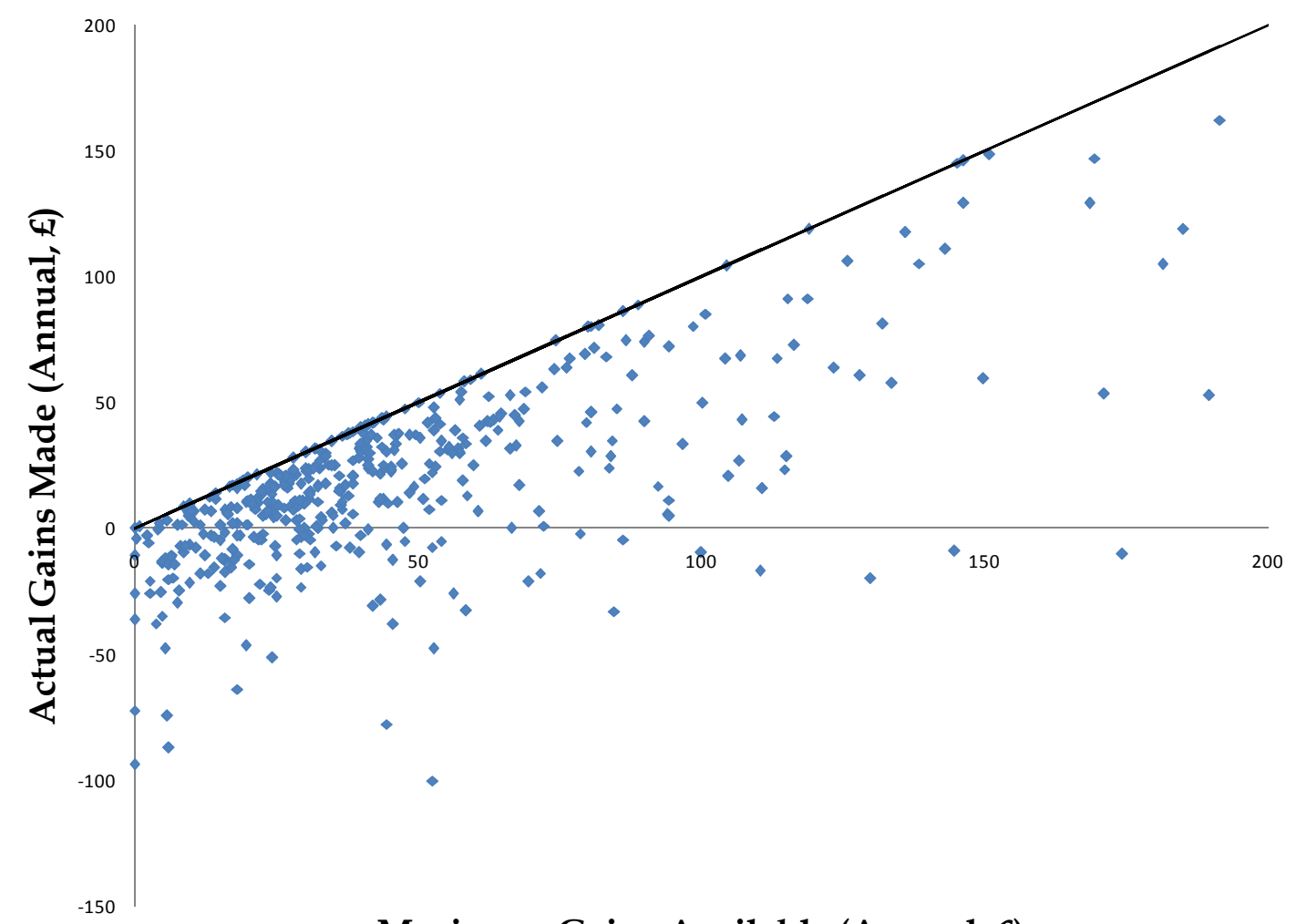

Maximum Gains Available (Anuual, $£$ )

The results shown in tables 3 and 4 are remarkably robust across datasets, across specifications and across consumption levels, providing support for the chosen measurement methodology. Despite including only decisions based exclusively on price, many consumers failed to switch to the cheapest supplier. Across datasets, specifications and consumption levels, the reported percentage of consumers selecting their cheapest supplier ranges between only 8 and 19\%. Although consumers as a whole made positive average gains of between $£ 16$ and $£ 22$ per annum, in aggregate, consumers appropriated only between 28 and $51 \%$ of the maximum benefits available to them. 
Table 3: Descriptive Statistics of the Gain Measures across a Range of Datasets and Specifications

\begin{tabular}{|c|c|c|c|c|c|c|c|c|c|c|c|c|}
\hline \multirow[t]{2}{*}{$\begin{array}{l}\text { Data } \\
\text { Specification }\end{array}$} & \multicolumn{2}{|l|}{$\mathrm{CCP}$} & \multicolumn{2}{|l|}{$\begin{array}{c}\text { EA } \\
\text { Pooled }\end{array}$} & \multicolumn{2}{|c|}{$\begin{array}{l}\text { EA } \\
\text { Oct } 99 \text { no change }\end{array}$} & \multicolumn{2}{|c|}{$\begin{array}{l}\text { EA } \\
\text { Oct } 99 \text { change }\end{array}$} & \multicolumn{2}{|c|}{$\begin{array}{c}\text { EA } \\
\text { Jun } 00 \text { no change }\end{array}$} & \multicolumn{2}{|c|}{$\begin{array}{c}\text { EA } \\
\text { Jun } 00 \text { change }\end{array}$} \\
\hline & Average & (StDev) & Average & (StDev) & Average & (StDev) & Average & (StDev) & Average & (StDev) & Average & (StDev) \\
\hline Number of Switchers & 154 & & 318 & & 318 & & 318 & & 318 & & 318 & \\
\hline Average Maximum Gains Available (annual, $£$ ) & 49.04 & $(39.20)$ & 44.22 & $(42.65)$ & 43.02 & $(42.84)$ & 41.42 & $(39.91)$ & 47.08 & $(42.85)$ & 45.35 & $(45.00)$ \\
\hline Average Mean Gains Available (annual, $£$ ) & 11.43 & $(31.16)$ & 8.80 & $(27.14)$ & 8.62 & $(28.02)$ & 7.01 & $(27.62)$ & 10.64 & $(29.25)$ & 8.92 & $(33.06)$ \\
\hline Average Actual Gains Made (annual, £) & 17.92 & $(43.18)$ & 19.41 & $(38.56)$ & 21.36 & $(41.57)$ & 19.75 & $(38.99)$ & 19.13 & $(35.61)$ & 17.40 & $(38.09)$ \\
\hline Average Mean Gains/Average Maximum Gains & 0.23 & & 0.20 & & 0.20 & & 0.17 & & 0.23 & & 0.20 & \\
\hline Average Actual Gains/Average Maximum Gains & 0.37 & & 0.44 & & 0.50 & & 0.48 & & 0.41 & & 0.38 & \\
\hline Proportion of Switchers with Perfect Gains & 0.18 & & 0.14 & & 0.18 & & 0.18 & & 0.10 & & 0.10 & \\
\hline Expected Proportion if Random Alternative Selected & 0.14 & & 0.07 & & 0.07 & & 0.07 & & 0.07 & & 0.07 & \\
\hline Proportion of Switchers with Negative Gain & 0.31 & $(0.46)$ & 0.25 & $(0.43)$ & 0.24 & $(0.43)$ & 0.26 & $(0.44)$ & 0.22 & $(0.41)$ & 0.29 & $(0.45)$ \\
\hline Average Gain given Negative Gain & -26.96 & $(32.99)$ & -17.56 & $(19.16)$ & -16.78 & $(20.77)$ & -19.23 & $(19.80)$ & -15.76 & $(16.93)$ & -18.47 & $(19.14)$ \\
\hline Proportion of Switchers with Non-Negative Gain & 0.69 & $(0.46)$ & 0.75 & $(0.43)$ & 0.76 & $(0.43)$ & 0.74 & $(0.44)$ & 0.78 & $(0.41)$ & 0.71 & $(0.45)$ \\
\hline Average Gain given Non-Negative Gain & 37.64 & $(30.55)$ & 31.85 & $(35.29)$ & 33.13 & $(39.27)$ & 33.52 & $(34.53)$ & 28.98 & $(33.24)$ & 31.78 & $(34.10)$ \\
\hline Proportion of Switchers with Dominated Choice & 0.01 & & 0.06 & & 0.07 & & 0.08 & & 0.03 & & 0.04 & \\
\hline
\end{tabular}

Maximum Gains Available refers to the change in surplus that would have been realised by a switcher had they switched to their cheapest alternative supplier Mean Gains Available refers to the change in surplus that a switcher would expect to gain by selecting a supplier randomly. The Proportion of Switchers with Perfect Gains refers to the proportion of consumers who appropriated all of the maximum gains available. This is compared to the expected probability of doing so had the consumer randomly selected an alternative supplier. The Proportion of Switchers with Dominated Choice refers to the proportion of consumers that switched to a tariff that could not be cheaper than their previous tariff for any level of consumption. 
Table 4: Comparing the Calculated Gain Measures with the Perturbed Consumption Levels

Data

Specification
$\mathrm{CCP}$

EA

Pooled
EA

Jun 00 no change Jun 00 change
Using Estimated Consumption Average Maximum Gains Available (annual, £) Average Actual Gains Made (annual, £)

Average Actual Gains/ Average Maximum Gains Proportion of Switchers with Perfect Gains Proportion of Switchers with Negative Gain

\section{Using Estimated Consumption -10\%}

Average Maximum Gains Available (annual, £) Average Actual Gains Made (annual, $£$ )

Average Actual Gains/ Average Maximum Gains

Proportion of Switchers with Perfect Gains

Proportion of Switchers with Negative Gain

\section{Using Estimated Consumption $\mathbf{+ 1 0 \%}$}

Average Maximum Gains Available (annual, £) Average Actual Gains Made (annual, $£$ )

Average Actual Gains/ Average Maximum Gains

Proportion of Switchers with Perfect Gains

Proportion of Switchers with Negative Gain

\begin{tabular}{|c|c|c|c|c|c|c|c|c|c|c|c|}
\hline Average & (StDev) & Average & (StDev) & Average & (StDev) & Average & (StDev) & Average & (StDev) & Average & (StDev) \\
\hline 49.04 & $(39.20)$ & 44.22 & $(42.65)$ & 43.02 & $(42.84)$ & 41.42 & $(39.91)$ & 47.08 & $(42.85)$ & 45.35 & $(45.00)$ \\
\hline 17.92 & (43.18) & 19.41 & $(38.56)$ & 21.36 & (41.57) & 19.75 & (38.99) & 19.13 & (35.61) & 17.40 & (38.09) \\
\hline 0.37 & & 0.44 & & 0.50 & & 0.48 & & 0.41 & & 0.38 & \\
\hline 0.18 & & 0.14 & & 0.18 & & 0.18 & & 0.10 & & 0.10 & \\
\hline 0.31 & $(0.46)$ & 0.25 & $(0.43)$ & 0.24 & $(0.43)$ & 0.26 & $(0.44)$ & 0.22 & $(0.41)$ & 0.29 & $(0.45)$ \\
\hline 47.47 & (37.56) & 42.04 & (38.00) & 41.17 & (41.66) & 40.97 & (36.27) & 42.44 & (38.21) & 43.57 & (35.85) \\
\hline 20.76 & (41.19) & 18.51 & (34.89) & 20.72 & $(40.53)$ & 19.27 & (37.05) & 17.42 & (31.99) & 16.64 & (29.99) \\
\hline 0.44 & & 0.44 & & 0.50 & & 0.47 & & 0.41 & & 0.38 & \\
\hline 0.16 & & 0.13 & & 0.19 & & 0.14 & & 0.10 & & 0.08 & \\
\hline 0.25 & $(0.43)$ & 0.23 & $(0.42)$ & 0.24 & $(0.43)$ & 0.24 & $(0.43)$ & 0.22 & $(0.41)$ & 0.23 & $(0.42)$ \\
\hline 53.30 & $(49.22)$ & 53.23 & (59.92) & 44.12 & (44.46) & 43.88 & (38.75) & 51.81 & $(47.86)$ & 73.09 & (108.62) \\
\hline 17.98 & (52.50) & 21.36 & (39.39) & 22.42 & $(42.48)$ & 20.82 & $(39.27)$ & 21.64 & (39.19) & 20.56 & $(36.63)$ \\
\hline 0.34 & & 0.42 & & 0.51 & & 0.47 & & 0.42 & & 0.28 & \\
\hline 0.14 & & 0.13 & & 0.19 & & 0.15 & & 0.10 & & 0.08 & \\
\hline 0.32 & $(0.47)$ & 0.22 & $(0.42)$ & 0.24 & $(0.43)$ & 0.24 & $(0.43)$ & 0.20 & $(0.40)$ & 0.21 & $(0.41)$ \\
\hline
\end{tabular}

Maximum Gains Available refers to the change in surplus that would have been realised by a switcher had they switched to their cheapest alternative supplier. The Proportion of Switchers with Perfect Gains refers to the proportion of consumers who appropriated all of the maximum gains available. 
They have only achieved a little more than would have been expected by switching to a randomly selected supplier; this would have offered consumers a 7 to $14 \%$ chance of picking the cheapest supplier ${ }^{9}$ and appropriated $17-23 \%$ of the maximum gains available.

More startlingly, even without taking into account the (financial or non financial) costs of making the switch, between 20 and $32 \%$ of consumers switched to a more expensive supplier, losing, on average, approximately £14-35 per year. Further, between 3 and $31 \%$ of these loss-making consumers actually switched to a 'dominated' tariff that could not have offered them a reduction in expenditure at any level of consumption. Finally, although it is difficult to make robust comparisons given the biases within each of the samples, our data provide no evidence that switching accuracy improved over the five years which elapsed between the two surveys.

\section{Potential Explanations}

The existence of search costs can explain why consumers did not select the best possible supplier, but the choice of a more expensive supplier remains puzzling. In this section we explore the validity of four possible explanations:

i) consumers exhibited some bias or preference for particular tariff structures;

ii) consumers were overly-attracted to suppliers offering dual-supply discounts;

iii) consumers were influenced by misleading sales activity; and

iv) consumers made genuine decision errors.

First, we consider the possibility that consumers' choices could be explained by a bias or preference for different tariff structures, as proposed in the literature documenting consumers' inaccurate tariff choices (e.g. Lambrecht and Skiera 2006). While the potential for such biases is limited in our market due to the narrow range of available tariff structures, we investigate the potential for consumers to have displayed a preference for tariff structures in

\footnotetext{
${ }^{9}$ This figure was calculated by finding the reciprocal of the number of alternative suppliers, averaged across consumers, given their respective regions. The probability doubles to 0.14 for the later CCP dataset due to the heavy market consolidation in recent years.
} 
two respects - the number of parts in the tariff (two or three) and whether or not there is a positive fixed fee. The evidence for such biases seems limited. Table $A 1$ in the appendix indicates that the estimated switching gains are largely unrelated to the choice of a two- or three-part tariff; the only weak evidence of such a bias occurs in the EA June specification where the 40 consumers who switched from a three- to a two-part tariff made significantly less accurate decisions than other switchers. Table 2 a shows that only $1 \%$ of consumers cited the existence of a zero fixed fee as a reason for switching and Table A2 in the Appendix shows that the estimated switching gains are, for the most part, unrelated to the magnitude of the chosen fixed fee. The only possibility of a bias occurs within the EA dataset where the 18 consumers who switched to a positive fixed fee made significantly worse decisions.

Second, we examine the possibility that consumers could have overestimated or have been overly sensitive to the dual-supply discount, as emphasised as an explanation in other contexts by Ausubel (1999) and Hossain and Morgan (2006). Despite excluding any consumer who cited the existence of a dualsupply discount as a reason for switching, this explanation may seem persuasive since $74 \%$ of the consumers in the sample who changed supplier switched to their gas provider. However, Table A2 in the appendix indicates that the dual-supplied switchers made, if anything, higher gains than the nondual supplied consumers, contradicting such an explanation. This evidence also eliminates the potential explanation that consumers may have switched to their gas supplier to receive some unmeasured non-price benefit.

Third, could consumers have been influenced by suppliers' mis-selling activity? Such an explanation is particularly plausible in the UK electricity market where there have been many allegations of mis-selling. While some complaints have been targeted at internet price comparison sites for misleading consumers by favouring certain suppliers ${ }^{10}$, most allegations have been aimed directly at the use of more direct mis-selling tactics by suppliers themselves. Indeed, the problem of aggressive or misleading 'cold-calling' or doorstep selling was considered so serious that several bodies conducted

\footnotetext{
${ }^{10}$ See http://business.guardian.co.uk/story/0,1975484,00.html. December $19^{\text {th }} 2006$.
} 
investigations (energywatch 2002, OFGEM 2002 and OFT 2004) and OFGEM subsequently fined London Electricity two million pounds ${ }^{11,12}$.

\subsection{Potential Mis-selling}

In this section we estimate whether the consumers' switching accuracy is related to two sets of test variables associated with potential mis-selling. We analyse each in turn. First, we explore whether the accuracy of consumers' switching decisions is adversely affected by the self-reported influence of suppliers' sales activity, as captured by two dummy variables from the EA survey. These correspond to consumers either reporting that they had been 'conned' into switching without their consent, conned $_{i}$, or that a sales agent had been active in their switching decision, agent ${ }_{i}{ }^{13}$. Consumers could cite both influences. To analyse how these variable relate to switching accuracy, two procedures are used to estimate variations of equation (6), where the gains from switching, $y_{i}^{s w g} *$, are modelled as a function of the two test variables agent $_{i}$ and conned $_{i}$ while controlling for a vector of consumer demographics, $D_{i}$, and each consumer's maximum available gains, $x_{i}^{\max }$.

\footnotetext{
${ }_{11}^{11}$ See http://news.bbc.co.uk/1/hi/business/2315115.stm. October 10th 2002.

${ }^{12}$ We find no evidence that those consumers who switched to London Electricity made significantly different gains to those who switched to other suppliers.

${ }^{13}$ The CCP data do not include these variables
} 
Table 5: Summary Statistics of the Demographic and Test Variables

\begin{tabular}{|c|c|c|c|}
\hline $\begin{array}{c}\text { Variable } \\
\text { Name } \\
\end{array}$ & $\begin{array}{cc}\text { Variable Definition } \\
\end{array}$ & Mean & (StDev) \\
\hline highsoc & "Household social grade: $\mathrm{A}, \mathrm{B}$ or C1 & 0.28 & $(0.45)$ \\
\hline midsoc & Household social grade: C2 or D & 0.49 & $(0.50)$ \\
\hline lowsoc & Household social grade: E & 0.22 & $(0.42)$ \\
\hline highinc & Household income: $£ 25000+$ & 0.13 & $(0.33)$ \\
\hline midinc & Household income: $£ 12500-£ 25000$ & 0.25 & $(0.43)$ \\
\hline lowinc & Household income: Less than $£ 12500$ & 0.43 & $(0.50)$ \\
\hline incref & Income status refused & 0.20 & $(0.40)$ \\
\hline age & Age of respondent & 44.86 & $(15.96)$ \\
\hline single & The household respondent is single & 0.15 & $(0.36)$ \\
\hline married & The household respondent is married & 0.62 & $(0.49)$ \\
\hline exmar & The household respondent is widowed or divorced & 0.23 & $(0.42)$ \\
\hline arrears & The household has electricty arrears & 0.04 & $(0.21)$ \\
\hline gassw & The household has previously switched gas supplier & 0.51 & $(0.50)$ \\
\hline rent & The household lives in rented accommodation & 0.43 & $(0.50)$ \\
\hline disable & The household has some form of disability benefit & 0.19 & $(0.47)$ \\
\hline agent & The household cited the influence of a sales agent & 0.11 & $(0.31)$ \\
\hline conned & The household switched without consent & 0.03 & $(0.18)$ \\
\hline \multirow[t]{2}{*}{$\mathrm{n}$} & The number of regional competitors & 14.75 & $(0.85)$ \\
\hline & Number of Observations & 318 & \\
\hline
\end{tabular}

A further variable, stable $e_{i}$, is included to investigate whether the measured switching accuracy of the sub group of consumers who reported highly price inelastic and stable consumption differs from the rest of the sample. This variable is later reported to be insignificantly different from zero, as discussed previously in Section 3.3. All relevant variables are described and summarised in Table 5.

$$
y_{i}^{\text {swg } *}=\beta_{1}+\text { agent }_{i} \beta_{2}+\text { conned }_{i} \beta_{2}+D_{i}{ }^{\prime} \beta_{3}+x_{i}^{\max } \beta_{4}+\text { stable }_{i} \beta_{5}+\varepsilon_{i}
$$

We use equation (6) to explore how consumers' switching gains depend on a set of independent variables in two ways. In the first case, $y_{i}^{\text {swg }} *$ is treated as a latent variable and we estimate the probability of a consumer making a positive gains using a probit model, and in the second case, we model the gains from switching as a continuous variable using OLS with heteroscedasticity-consistent standard errors. For robustness, the two estimations are conducted across each of the four EA data specifications and the results are reported in Tables 6 and 7. 
The self-reported incidences of sales and 'conning activity' have no significant effect on switching accuracy across all specifications. The estimations also indicate, in line with the findings of Economides et al (2006) and Miravete (2003), that very few demographic variables are useful predictors of the ability of consumers to make accurate decisions. Consumers living in rented property make less accurate decisions, probably because they expect to enjoy any benefits for a shorter time. Some of the specifications suggest that consumers with higher incomes (and those who declined to reveal their incomes) appropriate less of the available gains. Consumers are less likely to make a loss from switching suppliers if the maximum gains available are higher, a finding consistent with consumers having a higher incentive to make an accurate decision when the rewards from doing so are greater.

Table 6: Estimations of the Probability of Making a Positive Gain ${ }^{14}$

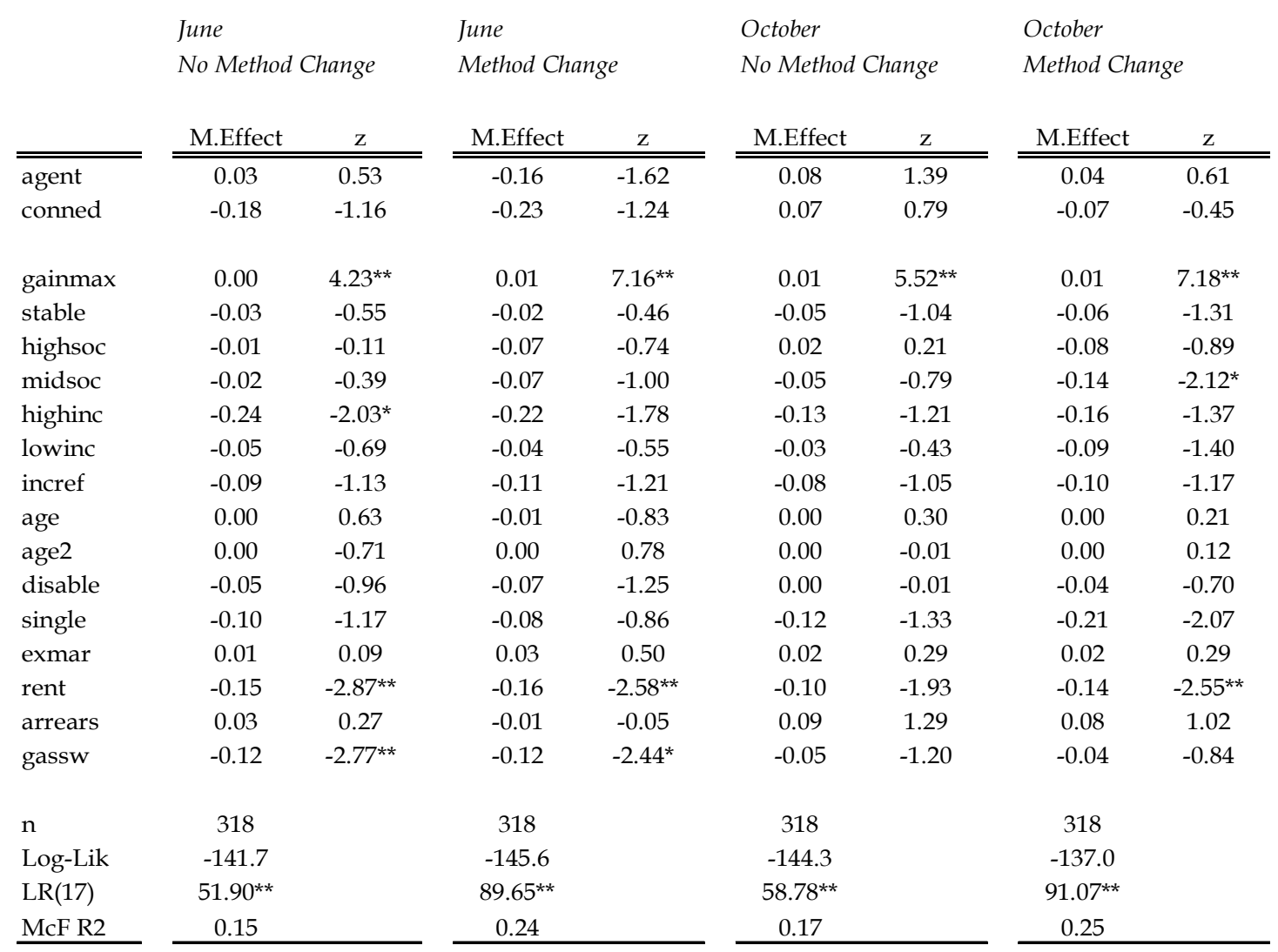

${ }^{14}$ All significant tests are indicated by ${ }^{*}$ for the $5 \%$ level and by ${ }^{* *}$ for the $1 \%$ level. Where applicable, all marginal effects are calculated for the average switcher relative to the base case of a consumer who is married, of low social class and with middle income. 
There is no evidence that previous experience improves decision accuracy. While Giulietti et al (2005) suggest that consumers are more likely to switch in a given market if they have previously switched in others, we find that a past experience of switching gas suppliers does nothing to improve (and sometimes reduces) switching accuracy.

To provide a further (less direct) test of the effects of mis-selling, the estimations are repeated with the inclusion of a different test variable - the number of competitors in each consumer's regional market. While conventional theories of consumer search do not predict any negative relationship between consumers' ability to appropriate the gains available

Table 7: Estimations of the Gains Made From Switching ${ }^{15}$

\begin{tabular}{|c|c|c|c|c|c|c|c|c|}
\hline & \multicolumn{2}{|c|}{$\begin{array}{l}\text { June } \\
\text { No Method Change }\end{array}$} & \multicolumn{2}{|c|}{$\begin{array}{l}\text { June } \\
\text { Method Change }\end{array}$} & \multicolumn{2}{|c|}{$\begin{array}{l}\text { October } \\
\text { No Method Change }\end{array}$} & \multicolumn{2}{|c|}{$\begin{array}{l}\text { October } \\
\text { Method Change }\end{array}$} \\
\hline & Coeff & $\mathrm{t}$ & Coeff & $\mathrm{t}$ & Coeff & $\mathrm{t}$ & Coeff & $\mathrm{t}$ \\
\hline agent & -0.70 & -0.14 & -2.57 & -0.49 & -2.10 & -0.41 & -3.34 & -0.58 \\
\hline conned & 0.22 & 0.05 & -0.03 & -0.01 & -3.64 & -0.45 & -3.75 & -0.49 \\
\hline gainmax & 0.01 & $9.43^{* *}$ & 0.01 & $11.05^{* *}$ & 0.01 & $14.24^{* *}$ & 0.01 & $10.55^{\star *}$ \\
\hline stable & 0.93 & 0.31 & 0.79 & 0.27 & -1.22 & -0.42 & -1.54 & -0.54 \\
\hline highsoc & -4.21 & -0.90 & -2.98 & -0.61 & -2.26 & -0.56 & -2.28 & -0.54 \\
\hline midsoc & -3.88 & -1.00 & -3.91 & -0.95 & -3.08 & -0.85 & -4.45 & -1.16 \\
\hline highinc & -13.90 & $-2.21^{*}$ & -13.23 & $-2.08^{*}$ & -1.08 & -0.19 & -0.36 & -0.06 \\
\hline lowinc & -5.12 & -1.39 & -5.80 & -1.50 & 1.89 & 0.52 & 1.55 & 0.41 \\
\hline incref & -13.57 & $-3.22^{* *}$ & -13.73 & $-3.22^{* *}$ & -6.87 & -1.57 & -5.63 & -1.41 \\
\hline age & -0.02 & -0.04 & -0.27 & -0.51 & 0.39 & 0.81 & 0.27 & 0.55 \\
\hline age2 & 0.00 & 0.18 & 0.00 & 0.66 & 0.00 & -0.25 & 0.00 & 0.04 \\
\hline disable & -4.87 & -1.30 & -4.52 & -1.16 & -6.53 & -1.77 & -6.30 & -1.71 \\
\hline single & -5.66 & -1.25 & -4.94 & -1.06 & -0.33 & -0.08 & -3.25 & -0.75 \\
\hline exmar & -0.49 & -0.16 & -0.33 & -0.10 & 0.16 & 0.05 & -0.44 & -0.13 \\
\hline rent & -6.08 & $-2.17^{*}$ & -4.54 & -1.58 & -8.40 & $-2.77^{* *}$ & -7.71 & $-2.46^{*}$ \\
\hline arrears & -8.98 & -1.21 & -8.22 & -1.08 & -4.17 & -0.66 & -4.48 & -0.72 \\
\hline gassw & -3.92 & -1.33 & -3.44 & -1.15 & -4.27 & -1.53 & -3.32 & -1.20 \\
\hline constant & 5.28 & 0.38 & 7.29 & 0.52 & -15.52 & -1.23 & -12.03 & -0.92 \\
\hline $\mathrm{n}$ & 318 & & 318 & & 318 & & 318 & \\
\hline $\mathrm{F}(17,300)$ & $10.34^{* *}$ & & $14.06^{* *}$ & & $18.37^{* *}$ & & $14.06^{* *}$ & \\
\hline McF R2 & 0.58 & & 0.61 & & 0.68 & & 0.64 & \\
\hline
\end{tabular}

${ }^{15}$ All significant tests are indicated by ${ }^{*}$ for the $5 \%$ level and by ** for the $1 \%$ level. Where applicable, all coefficients are estimated relative to the base case of a consumer who is married, of low social class and with middle income. 
and the number of competitors ${ }^{16}$, it is reasonable to conjecture that mis-selling strategies may be more attractive to firms as the profits from more standard forms of competition are reduced from increases in the number of suppliers. In a related sense, recent work by Spiegler (2005) illustrates how firms face an increased incentive to obfuscate by increasing the variance of their utility offers when faced with more competitors, while Miravete (2007) offers evidence to suggest that firms are more likely to employ dominated tariff options when competition increases. To test for such an effect, we exploit the fact that the number of regional competitors varied between twelve and sixteen at the time of the EA survey ${ }^{17}$. If mis-selling were an explanation, consumers would make less accurate decisions in regional markets with a higher number of competing suppliers ${ }^{18}$. Formally, the two estimation procedures are repeated with the replacement of the previous test variables, agent $_{i}$ and conned $_{i}$, with the new test variable, $n_{i}$, measuring the number of regional suppliers faced by each consumer ${ }^{19}$. As the estimated coefficients differ very little from those previously reported, only the effects of the test variable are displayed in Tables 8 and 9.

\footnotetext{
${ }^{16}$ Indeed, for any given price distribution and cost of search, a consumer should accept any discovered price below the optimal reservation price which is defined independently from the number of firms (Kohn and Shavell 1974).

${ }^{17}$ These numbers refer to the number of large firms that were patronised by consumers in the EA sample and do not include some smaller firms that also operated across all regions. Including such firms in the estimations increases the number by a constant and does not affect our qualitative results. No such variation in firm numbers existed at the time of the CCP survey due to later market consolidation.

${ }^{18} \mathrm{It}$ is feasible, but unlikely given the limited variation in the number of firms, that consumer inaccuracy may also be prompted by a 'choice overload' effect from the increased complexity of the decision (e.g. lyengar and Lepper 2000 and lyengar and Kamenica 2007).

${ }^{19}$ Both the number of competitors and the maximum gains can be included as explanatory variables, since they have a negligible correlation of approximately 0.02 across specifications.
} 
Table 8: Estimated Marginal Effects of the Number of Regional Competitors on the Probability of Switching to Make a Positive Gain ${ }^{20}$

\begin{tabular}{|c|c|c|c|c|c|c|c|c|}
\hline \multirow{2}{*}{\multicolumn{3}{|c|}{$\begin{array}{l}\text { June } \\
\text { No Method Change }\end{array}$}} & \multirow{2}{*}{\multicolumn{2}{|c|}{$\begin{array}{l}\text { June } \\
\text { Method Change }\end{array}$}} & \multirow{2}{*}{\multicolumn{2}{|c|}{$\begin{array}{l}\text { October } \\
\text { No Method Change }\end{array}$}} & \multirow{2}{*}{\multicolumn{2}{|c|}{$\begin{array}{l}\text { October } \\
\text { Method Change }\end{array}$}} \\
\hline & & & & & & & & \\
\hline & M.Effect & $\mathrm{z}$ & M.Effect & $\mathrm{z}$ & M.Effect & $\mathrm{z}$ & M.Effect & $\mathrm{z}$ \\
\hline & -0.01 & -0.54 & 0.03 & -0.96 & -0.04 & -1.43 & -0.05 & -1.77 \\
\hline
\end{tabular}

Table 9: Estimated Marginal Effects of the Number of Regional Competitors on the Actual Gains Made from Switching

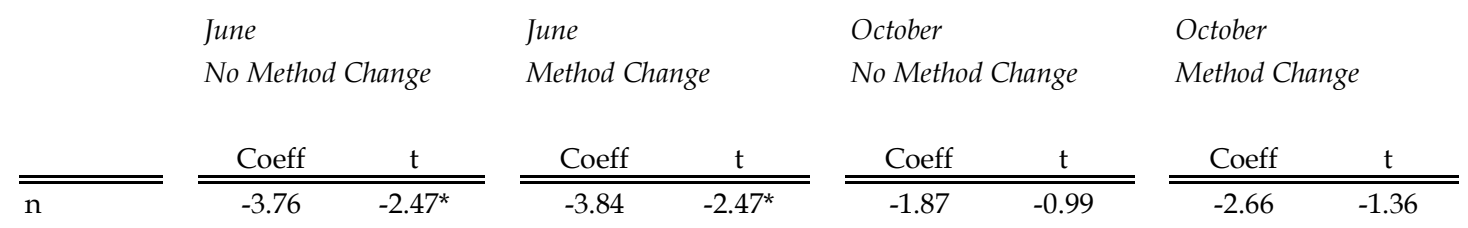

While there is no evident relationship between the number of regional competitors and the probability of making a positive gain by switching, Table 9 suggests that in two out of four specifications, consumers appropriated relatively less of the maximum available gains in regions with a higher number of suppliers. However as much of the variation in the number of regional competitors arises, however, from the relative lack of market entry in the two Scottish electricity regions, such a finding is also consistent with the presence of some unobserved characteristic of firms or consumers within the Scottish markets. The results are therefore unclear and do not provide direct evidence that mis-selling explains the inaccuracy of consumers' switching decisions.

The evidence presented in this section does not indicate that consumers' poor switching choices are explained by tariff biases or suppliers' mis-selling activity. We deduce that much of the switching inaccuracy results from genuine consumer confusion and decision error.

${ }^{20}$ Significance is denoted at $5 \%$ by * and at $1 \%$ by **. 


\section{Conclusion}

Using two independent datasets from the UK electricity market our results show that the capacity of consumers to choose efficiently between suppliers may be limited, even when switching purely for price reasons. While the results are not necessarily representative of the general population, our estimations show that, at best, a fifth of the consumers in our samples actually lost surplus as a result of switching; and that, in aggregate, switching consumers appropriated only half of the maximum gains available to them. Such a failure of consumers to compare accurately between alternative suppliers can damage their welfare, both directly in lost savings, and indirectly by delivering firms with a source of market power. Indeed, together with the well established effects of switching costs in reducing the willingness of consumers to switch suppliers, such behaviour may seriously impede the competitive process, even after a market has been liberalised or made subject to standard competition policy (as recently argued by Waterson 2003).

We have examined and rejected several explanations of consumer errors, including preferences for particular tariff structures or dual fuel supply, and misleading sales activities by firms. Instead, despite the apparent simplicity and transparency of the market, consumers' poor choices seem more consistent with an explanation of pure decision error. This finding casts doubt on the ability of consumers to generate competitive forces through accurate switching decisions and raises many important policy concerns. Future research would be valuable in understanding how competition and consumer authorities should respond to consumer errors, if at all, and in investigating the implications for current policies aiming to increase competition in less familiar markets, such as health and education. 


\section{References:}

Agarwal S., Chomsisengphet S., Liu C. and Souleles N.S. (2006) "Do Consumers Choose the Right Credit Contracts?" Federal Reserve Bank of Chicago Working Paper 2006-11

Armstrong M. and Spiegler R. (2007) "Boundedly Rational Consumers" June 2007

Ausubel L.M. (1999) "Adverse Selection in the Credit Market" Working Paper University of Maryland

Baye M.R., Morgan J. and Scholten P. (forthcoming) "Information, Search and Price Dispersion" in Handbook on Economics and Information Systems, Elsevier

Baker P., Blundell R. and Micklewright J. (1989) "Modelling Household Energy Expenditure Using Micro-Data" Economic Journal vol.99 p.720-738

Chang Y. and Waddams Price C. (forthcoming) "Search and Switching Across Relationship Markets" ESRC Centre for Competition Policy Working Paper

Cooke D., Ferrari A., Giuletti M., Sharratt D. and Waddams Price C. (2001) "Affording Gas and Electricity: Self Disconnection and Rationing by Prepayment and Low Income Credit Consumers and Company Attitudes to Social Action" www.ccp.uea.ac.uk/publications.asp\#2001

Della Vigna S. and Malmendier U. (2004) "Contract Design and Self-Control: Theory and Evidence" Quarterly Journal of Economics vol. 119(2) p.353-402

Della Vigna S. and Malmendier U. (2006) "Paying Not to Go to the Gym" American Economic Review vol. 96 (3) p. 694-719

Economides N., Seim K. and V.B. Viard (2006) "Quantifying the Benefits of Entry into Local Phone Service" NET Institute Working Paper, August 2006

Ellison G. and Ellison S.F. (2005) "Search, Obfuscation and Price Elasticities on the

Internet"Working Paper February 2005

Ellison G. and Ellison S.F. (2006) "Internet Retail Demand: Taxes, Geography and

Online-Offline Competition"Working Paper April 2006

energywatch (2002) "Doorstep and Telephone Selling: A Guide for Gas and Electricity Consumers" Information Sheet

Farrell J. and Klemperer P. (2006) "Coordination and Lock-In: Competition with Switching Costs and Network Effects" Forthcoming in 
Handbook of Industrial Organization Vol 3, M. Armstrong and R. Porter (eds), North-Holland

Gabaix X., Laibson D. and Li H. (2005) "Extreme Value Theory and the Effects of

Competition on Profits"Working Paper March 2005

Giulietti M., Waddams Price C. and Waterson M. (2005) "Consumer Choice and Competition Policy: A Study of UK Energy Markets" Economic Journal vol. 115 p.949-968

Hossain T. and Morgan J. (2006a) "Plus Shipping and Handling: Revenue (Non) Equivalence in Field Experiments on eBay" Advances in Economic Analysis and Policy vol. 6(2)

lyengar S.S. and Lepper M. (2000) "When Choice is Demotivating: Can One Desire

Too Much of a Good Thing?" Journal of Personality and Social Psychology vol.79 p.995-1006

lyengar S.S. and Kamenica E. (2007) "Choice Overload and Simplicity Seeking" Working Paper February 2007

Kohn M.G. and Shavell S. (1974) "Optimal Adaptive Search" Journal of Economic Theory vol. 9 p.93-123

Lambrecht A. and Skiera B. (2006) "Paying Too Much and Being Happy About It: Existence, Causes and Consequences of Tariff Choice Biases" Journal of Marketing Research, forthcoming, May 2006

Miravete E.J. (2003) "Choosing the Wrong Calling Plan? Ignorance and Learning" American Economic Review vol. 93(1) p.297-310

Miravete E.J. (2007) “The Doubtful Profitability of Foggy Pricing" Working Paper July 2007

OFGEM (2002) "OFGEM Keeps up Pressure on Suppliers to Reduce Misselling" The Office of Gas and Electricity News, Press Release 30 January 2002

OFGEM (2004) “Domestic Competitive Market Review” April 2004

OFT (2004) "Doorstep Selling: A Report on the Market Study" Office of Fair Trading, May 2004

Sonnemans J. (1998) "Strategies of Search" Journal of Economic Behavior and Organization vol.35, p.309-332

Spiegler R. (2005) "Competition Over Agents with Boundedly Rational Expectations" Theoretical Economics vol. 1(2) p.207-231 
Tenerio R. and Cason T.N. (2002) "To Spin or Not to Spin? Natural and Laboratory Experiments from The Price is Right" Economic Journal vol.112 p.170-195

Waddams-Price C. (2003) "Spoilt for Choice? The Costs and Benefits of Opening UK Residential Energy Markets"Working Paper December 2003

Waterson M. (2003) "The Role of Consumers in Competition and Competition Policy" International Journal of Industrial Organization vol.21 p. 129-150 


\section{Appendix 1: Identifying tariffs for the EA dataset}

Two aspects of the EA dataset make it difficult to identify directly the exact set of tariffs relevant for each consumer's switching decision. The first is the exact date of the switching decision. (Economides et al (2006) faced the same problem and were forced to assume that consumers had switched at the date of information collection.) The second problem arises from the timing of the change in payment method for the $32 \%$ of consumers who reported such a change. To calculate the gains on switching we need to know whether they, changed their payment method before, after, or at the same time as they switched suppliers. To resolve these uncertainties and to enhance the robustness of our findings we report the results over four different specifications. As the EA survey was conducted in March-August 2000, very soon after liberalisation, consumers could have switched using one of only four possible tariff sets, namely those commencing in June 1999, October 1999, April 2000 and June 2000. Consumers are most likely to have switched under either the October 1999 tariffs, as these were stable for the longest period (October 1999 -April 2000), or the June 2000 tariffs, as the proportion of consumers switching suppliers was rising over the period. Using both of these time periods, the calculations are then made under two further assumptions to provide a total of four specifications. These two assumptions concern whether the $32 \%$ of consumers who had changed their payment method, changed either before they switched suppliers (the consumers traded with both their original and current supplier under their current payment method) or, perhaps more realistically, at the time of switching (the consumers traded with their original supplier using their previous payment method but traded with their current supplier under their current payment method) ${ }^{21}$. The four specifications are respectively labelled as Oct99nochange, Oct99change, Jun00nochange and Jun00change (see appendix for further details).

\footnotetext{
${ }^{21}$ The most commonly reported method changes are moving from credit to direct debit $(41 \%)$ and credit to prepayment $(38 \%)$. We do not allow for the unlikely possibility that the change was made after the process of changing suppliers.
} 


\section{Appendix $\mathbf{2}^{22}$ :}

\section{Table A1: Switching Accuracy by Changes in Chosen Tariff Structure}

\begin{tabular}{|c|c|c|c|c|c|c|}
\hline \multirow[b]{2}{*}{ CCP Data } & \multicolumn{2}{|c|}{$\begin{array}{l}\text { No Change in } \\
\text { Tariff Structure }\end{array}$} & \multicolumn{2}{|c|}{$\begin{array}{l}\text { Three-part to } \\
\text { Two-part }\end{array}$} & \multicolumn{2}{|c|}{$\begin{array}{l}\text { Two-part to } \\
\text { Three-part }\end{array}$} \\
\hline & Average & (StDev) & Average & (StDev) & Average & (StDev) \\
\hline Number of Switchers & 74 & & 50 & & 30 & \\
\hline Proportion of Switchers & 0.48 & & 0.32 & & 0.19 & \\
\hline Average Maximum Gains Available (annual, $£$ ) & 44.25 & $(32.46)$ & 53.16 & $(44.10)$ & 53.99 & (45.35) \\
\hline Average Actual Gains Made (annual, $£$ ) & 14.82 & (41.96) & 23.18 & (50.25) & 16.80 & (32.63) \\
\hline Average Actual Gains/Average Maximum Gains & 0.33 & & 0.44 & & 0.31 & \\
\hline Proportion of Switchers with Negative Gain & 0.30 & $(0.46)$ & 0.28 & $(0.45)$ & 0.37 & $(0.49)$ \\
\hline EA Data (Pooled June Specification) & Average & (StDev) & Average & (StDev) & Average & (StDev) \\
\hline Number of Switchers & 169 & & 40 & & 109 & \\
\hline Proportion of Switchers & 0.53 & & 0.13 & & 0.34 & \\
\hline Average Actual Gains Made (annual, $£$ ) & 12.50 & $(29.24)$ & $-3.38^{* *}$ & $(27.69)$ & $35.14^{* *}$ & $(41.33)$ \\
\hline Average Maximum Gains Available (annual, $£$ ) & 42.17 & $(36.40)$ & 34.69 & $(29.29)$ & $56.72^{*}$ & $(54.29)$ \\
\hline Average Actual Gains/Average Maximum Gains & 0.30 & & -0.10 & & 0.62 & \\
\hline Proportion of Switchers with Negative Gain & 0.31 & $(0.45)$ & $0.55^{* *}$ & $(0.46)$ & $0.06^{* *}$ & $(0.20)$ \\
\hline EA Data (Pooled October Specification) & Average & (StDev) & Average & (StDev) & Average & (StDev) \\
\hline Number of Switchers & 226 & & 78 & & 14 & \\
\hline Proportion of Switchers & 0.71 & & 0.25 & & 0.04 & \\
\hline Average Actual Gains Made (annual, $€$ ) & 19.85 & $(43.01)$ & 23.28 & $(24.11)$ & 16.84 & $(32.72)$ \\
\hline Average Maximum Gains Available (annual, $£$ ) & 41.42 & $(42.66)$ & 41.85 & $(28.43)$ & 57.19 & $(47.58)$ \\
\hline Average Actual Gains/Average Maximum Gains & 0.48 & & 0.56 & & 0.29 & \\
\hline Proportion of Switchers with Negative Gain & 0.27 & $(0.43)$ & 0.18 & $(0.37)$ & 0.21 & $(0.43)$ \\
\hline
\end{tabular}

\footnotetext{
${ }^{22}$ Notes for Tables A1-A3. ${ }^{* *}$ and ${ }^{*}$ are used to indicate a significant difference in means under both a standard t-test and a non-parametric Mann-Whitney $U$ test at the $5 \%$ and $1 \%$ respectively.
} 


\section{Table A2: Switching Accuracy by Changes in Chosen Fixed Fee Tariff Structure ${ }^{23}$}

\begin{tabular}{|c|c|c|c|c|c|c|}
\hline \multirow[b]{2}{*}{ CCP Data } & \multicolumn{2}{|c|}{$\begin{array}{l}\text { No Change in } \\
\text { Tariff Structure }\end{array}$} & \multicolumn{2}{|c|}{$\begin{array}{l}\text { Pos. Fixed Fee to } \\
\text { Zero Fixed Fee }\end{array}$} & \multicolumn{2}{|c|}{$\begin{array}{l}\text { Zero Fixed Fee } \\
\text { to Pos. Fixed Fee }\end{array}$} \\
\hline & Average & (StDev) & Average & (StDev) & Average & (StDev) \\
\hline Number of Switchers & 69 & & 29 & & 56 & \\
\hline Proportion of Switchers & 0.45 & & 0.19 & & 0.36 & \\
\hline Average Actual Gains Made (annual, $£$ ) & 19.46 & $(43.29)$ & 19.43 & (32.43) & 15.25 & $(48.19)$ \\
\hline Average Maximum Gains Available (annual, $£$ ) & 46.97 & (33.38) & 55.08 & $(45.67)$ & 48.46 & $(42.55)$ \\
\hline Average Actual Gains/Average Maximum Gains & 0.41 & & 0.35 & & 0.31 & \\
\hline Proportion of Switchers with Negative Gain & 0.28 & $(0.45)$ & 0.28 & $(0.45)$ & 0.36 & $(0.48)$ \\
\hline EA Data (Pooled June Specification) & Average & (StDev) & Average & (StDev) & Average & (StDev) \\
\hline Number of Switchers & 156 & & 144 & & 18 & \\
\hline Proportion of Switchers & 0.49 & & 0.45 & & 0.06 & \\
\hline Average Actual Gains Made (annual, £) & 8.79 & (29.44) & $32.78^{* *}$ & $(37.93)$ & $-15.72^{* *}$ & (22.08) \\
\hline Average Maximum Gains Available (annual, £) & 39.93 & (35.04) & $53.73^{* *}$ & $(50.27)$ & 40.64 & (40.53) \\
\hline Average Actual Gains/Average Maximum Gains & 0.22 & & 0.61 & & -0.39 & \\
\hline Proportion of Switchers with Negative Gain & 0.36 & $(0.46)$ & $0.08^{* *}$ & $(0.23)$ & $0.78^{\star *}$ & $(0.39)$ \\
\hline
\end{tabular}

\section{Table A3: Switching Accuracy of Dual and Non-Dual Supplied Consumers}

\begin{tabular}{|c|c|c|c|c|}
\hline \multirow[b]{2}{*}{ CCP Data } & \multicolumn{2}{|c|}{ Not Dual Supplied } & \multicolumn{2}{|c|}{ Dual Supplied } \\
\hline & Average & (StDev) & Average & (StDev) \\
\hline Number of Switchers & 29 & & 125 & \\
\hline Proportion of switchers & 0.19 & & 0.81 & \\
\hline Average Actual Gains Made (annual, $£$ ) & 15.36 & $(62.37)$ & 18.52 & (37.68) \\
\hline Average Maximum Gains Available (annual, £) & 48.07 & (49.43) & 49.27 & (36.66) \\
\hline Average Actual Gains/Average Maximum Gains & 0.32 & & 0.38 & \\
\hline Proportion of Switchers with Negative Gain & 0.45 & $(0.51)$ & 0.27 & $(0.45)$ \\
\hline EA Data (Pooled Specifications) & Average & (StDev) & Average & (StDev) \\
\hline Number of Switchers & 96 & & 222 & \\
\hline Proportion of switchers & 0.30 & & 0.70 & \\
\hline Average Actual Gains Made (annual, $£$ ) & $10.45^{* *}$ & (43.17) & 23.29 & (30.95) \\
\hline Average Maximum Gains Available (annual, $£$ ) & 46.87 & (50.42) & 43.07 & (34.82) \\
\hline Average Actual Gains/Average Maximum Gains & 0.22 & & 0.54 & \\
\hline Proportion of Switchers with Negative Gain & $0.39^{* *}$ & $(0.40)$ & 0.19 & $(0.34)$ \\
\hline
\end{tabular}

\footnotetext{
${ }^{23}$ Tariffs with positive fixed fees were so common within the EA Pooled October Specification that all consumers switched to such tariffs, preventing us from testing such a hypothesis.
} 